\title{
História da Hemoterapia no Brasil
}

\section{History of Brazilian Hemotherapy}

Pedro C. Junqueira ${ }^{1,2}$

Jacob Rosenblit ${ }^{1}$

Nelson Hamerschlak
A transfusão de sangue teve dois periodos: um empírico, que vai até 1900, e outro cientifico, de 1900 em diante. No Brasil, em 1879, um relato discutia se a melhor transfusão seria com sangue de animais para humanos ou entre seres humanos. $\mathrm{Na}$ era cientifica, os pioneiros da hemoterapia foram cirurgiões do Rio de Janeiro. Por volta de 1920 surgem os primeiros serviços organizados e de constituição bastante simples. Destaca-se, nos anos 40, no Rio de Janeiro, o STS (Serviço de Transfusão de Sangue) por ter, além da conotação assistencial, atividades científicas. No final desta década, é promovido o I Congresso Paulista de Hemoterapia, que forneceu as bases para a fundação da Sociedade Brasileira de Hematologia e Hemoterapia, em 1950. Em 1965 cria-se, por iniciativa do Ministério da Saúde, a Comissão Nacional de Hemoterapia, estabelecendo normas para proteção dos doadores e receptores de sangue. Mesmo assim, chegamos em 1979 com um sistema desorganizado e desigual na qualidade dos serviços prestados. Nos anos 80, a criação da Politica Nacional do Sangue, a campanha da doação altruísta de sangue da SBHH e a Constituição de 1980 deram outra dimensão à hemoterapia brasileira. Chegamos então ao contemporâneo onde a desastrosa ocorrência da AIDS em pacientes transfundidos obrigou a novos conceitos e cuidados. Além disso, outros fatos importantes contribuíram para a hemoterapia no País, como o conceito da hemoterapia clínica, fatores econômicos, desenvolvimento da genética molecular e biotecnologia, a terapia celular, a renovação de equipamentos, a automação e computação, os sistemas da qualidade e o interesse do hemoterapeuta por áreas cientificas de ponta. Rev. bras. hematol. hemoter. 2005;27(3):201-207.

Palavras-chave: História da transfusão de sangue; bancos de sangue; hemoterapia no Brasil.
"Será tempo de apreciarmos nossas conquistas e nossos defeitos, nestes 50 anos, e tentar prever o radioso futuro do século $X X I^{\prime \prime}$

Pedro Clóvis Junqueira XXIV Congresso Brasileiro de Hematologia Maio de 2000

\section{Os Primórdios}

Fazer um histórico da Hemoterapia em nosso País é uma tarefa difícil, mas absolutamente necessária, tendo em vista o grau de excelência na área que a especialidade vem, paulatinamente, atingindo. Por outro lado, sabemos também que muitos fatos e nomes importantes podem ter sido, involuntariamente, omitidos. Por este motivo, consideramos este um capítulo vivo e solicitamos aos profissionais da área que nos enviem documentos e histórias que possam ser acrescentadas em futuras edições e iniciativas sobre o tema.

\footnotetext{
Correspondência para: Nelson Hamerschlak

Hospital Israelita Albert Einstein

Av Albert Einstein, 627 Sala 1203

05651-901 - São Paulo - SP

E-mail:hamer@einstein.br
}

${ }^{1}$ Ex-presidente da Sociedade Brasileira de Hematologia e Hemoterapia.

${ }^{2}$ Presidente Honorário da Sociedade Brasileira de Hematologia e Hemoterapia. 
A prática transfusional no Brasil continua evoluindo, como ocorre em outros países do mundo, seguindo, entretanto, as características de nosso país, nem sempre atualizado, e da nossa medicina. Deste modo, o Rio de Janeiro, como capital do Brasil até 1960, e São Paulo, por ser a maior cidade da América Latina, lideraram a evolução da Hemoterapia brasileira. Outros estados desempenharam importantes papéis nesta evolução, como Bahia, Pernambuco e Porto Alegre.

A transfusão de sangue, no mundo, teve dois períodos: um empírico, que vai até 1900 , e outro científico, de 1900 em diante.

Na era "pré-científica" surgiu o primeiro relato acadêmico sobre Hemoterapia no Brasil. Trata-se de uma tese de doutoramento apresentada à Faculdade de Medicina do Rio de Janeiro, em 27 de setembro de 1879, de autoria de José Vieira Marcondes, fillho legítimo do Barão e da Baronesa de Taubaté. ${ }^{1}$ Rejeitada por ser muito polêmica foi, entretanto, sustentada na Faculdade de Medicina da Bahia, em 30 de dezembro de 1879. Esta tese é uma monografia descrevendo experiências empíricas, realizadas até aquela época sobre a transfusão de sangue, onde se discute se a melhor transfusão seria a do animal para o homem ou entre os seres humanos. $\mathrm{O}$ aspecto interessante deste trabalho é a descrição detalhada de uma reação hemolítica aguda, com alterações renais e presença da hemoglobina na urina.

$\mathrm{Na}$ "era científica" da transfusão de sangue, após a descoberta dos grupos sangüíneos, por Karl Landsteiner, em 1900, transfusões eram feitas por cirurgiões como Carrel, Crille, De Bakey e outros reconhecidos como inovadores mundiais. Entre nós, Brandão Filho e Armando Aguinaga foram os pioneiros nesta prática, no Rio de Janeiro. Mas o melhor relato desta época ocorreu em Salvador (Bahia) quando o professor de Clínica Médica, Garcez Fróes, fez a primeira transfusão de sangue, usando o aparelho de Agote, improvisado por ele, transfundindo $129 \mathrm{ml}$ de sangue do doador João Cassiano Saraiva, servente do hospital, em uma paciente operada de pólipo uterino com metrorragia importante (Figura 1). Em 1916, Isaura Leitão defendeu sua tese sobre "Transfusão Sangüínea", relatando este caso e descrevendo outros três relatos semelhantes.

Pouco depois surgem serviços especializados, de organizações simples, constando de um médico transfusionista e de um corpo de doadores universais, de indivíduos do grupo sangüíneo universal $(\mathrm{O})$, que eram selecionados e examinados, para comprovação de suas boas condições de saúde. O instrumento utili- zado para passar o sangue do doador ao receptor, por sua simplicidade de manuseio e facilidade de esterilização, era a seringa de Jubé (Figura 2).

Até a década de 40, já existiam no Brasil vários serviços de transfusão, mas um merece destaque: o Serviço de Transfusão de Sangue (STS), fundado no Rio de Janeiro, em 1933, por Nestor Rosa Martins, Heraldo Maciel e Affonso Cruvinel Ratto. Estes colegas aliaram à assistência médica um enfoque científico voltado ao exercício da especialidade e às transfusões de sangue de forma geral. O sucesso deste modelo e a eficiência do atendimento resultaram na criação, em 1937, de várias filiais, entre elas a de Juiz de Fora, sob a direção de Côrtes Villela e a de Salvador, de Menandro Novais e Estácio Gonzaga. Outras foram de curta duração, como a de Arnaldo Marques, em Recife.
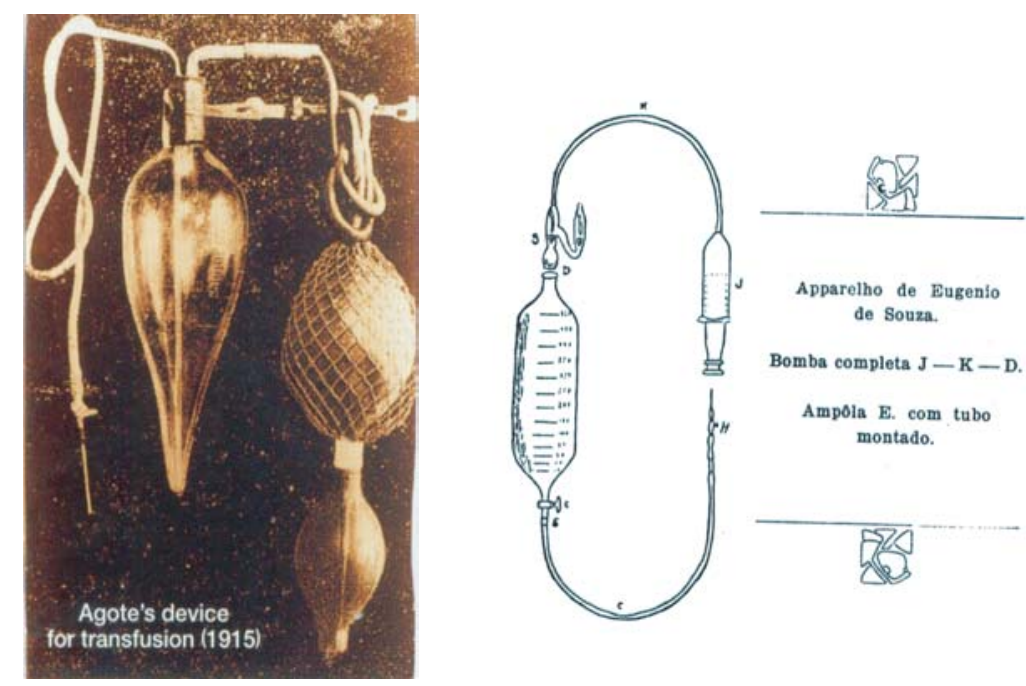

Figura 1. Aparelho de Agote e adaptação de Eugenio de Souza

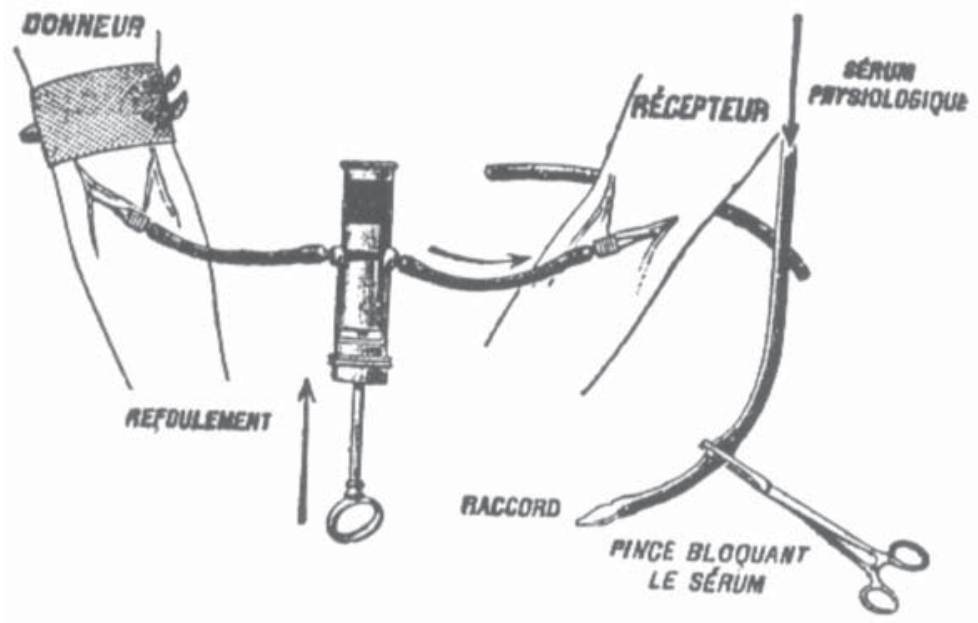

Figura 2. Seringa de Jubé 
Este modelo resultou em artigo científico publicado na Revista Brasil Médico (Figura 3), no qual os autores destacavam o papel do sangue sobre seus aspectos científico, religioso, cultural, político, moral e jurídico. Discorriam, ainda, sobre as diversas técnicas de transfusões de sangue, organização de serviços transfusionais e detalhando a organização do STS, do Rio de Janeiro. Destaques importantes

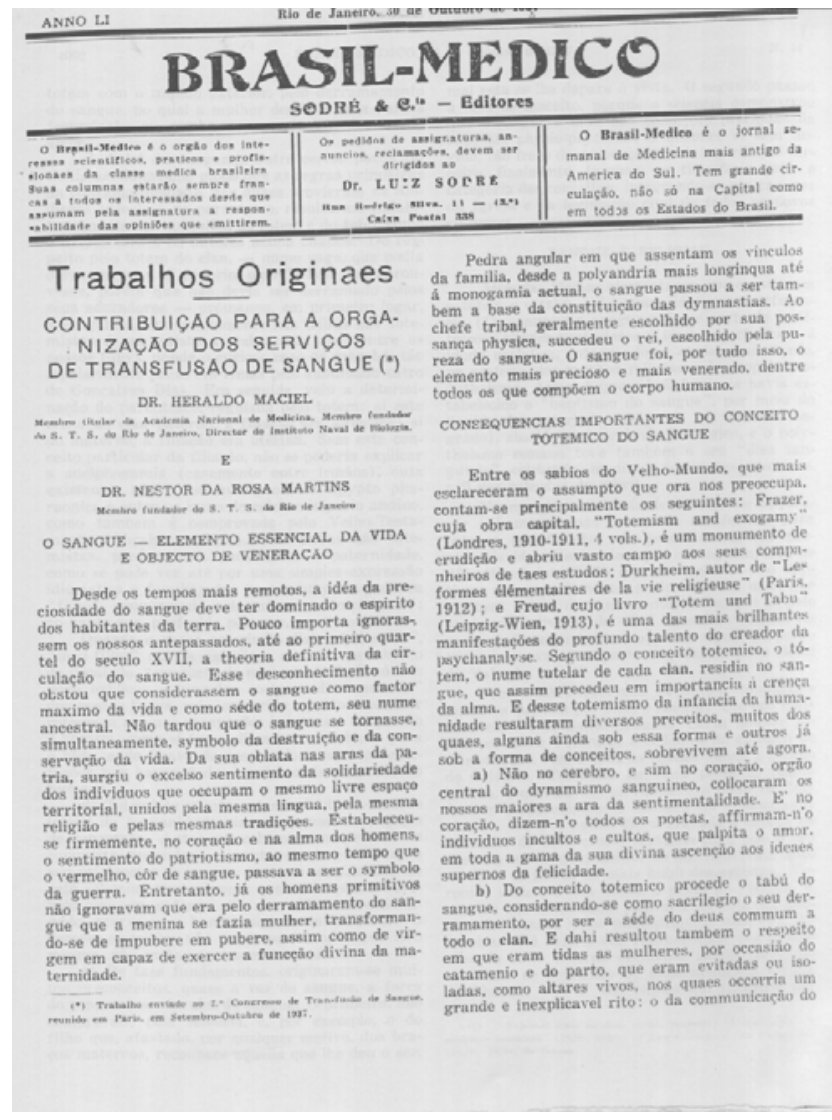

Figura 3. Artigo na Revista Brasil Médico. Serviço de Transfusão de Sangue

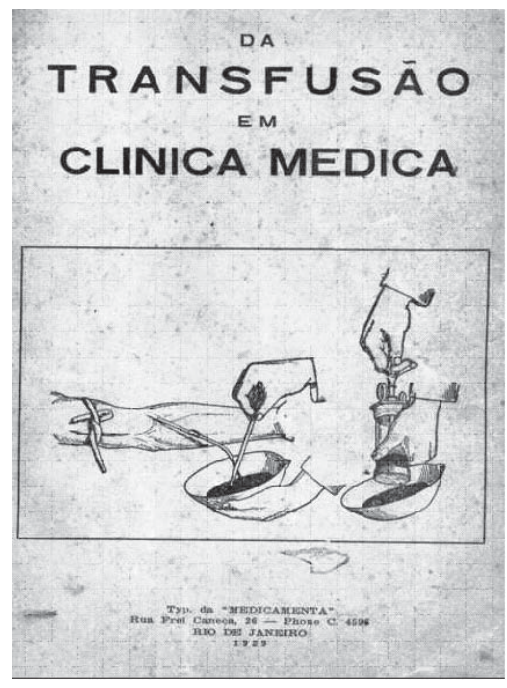

Figura 4. Tese de Garcia Junior- 1929 do artigo eram os cuidados com a seleção de doadores, da qualidade das transfusões, e a necessidade de estar a assistência transfusional acoplada a um centro de estudos e investigações. Era citada uma mesa portátil, criada por Calda Bitar, que permitia maior segurança e comodidade na operação de transfundir o sangue de braço a braço.

Curioso no artigo é o relato sobre honorários médicos transfusionais e o pagamento a doadores de sangue. Os altamente selecionados eram remunerados a 500 réis por centímetro cúbico de sangue doado ou, no caso de doadores imunizados, a 750 réis $/ \mathrm{mm}^{3}$. Afirmam veementemente que não admitiam doadores benévolos, nem de emergência. Diziam que se o paciente não tivesse recursos para pagar os serviços e exames relativos às transfusões, estaria isento de qualquer débito; no entanto, o pagamento ao doador deveria ser garantido pelo serviço de transfusão e não pelo paciente, que poderia retardar o pagamento, o que não seria justo para com o doador. ${ }^{2}$ Desta época merece destaque a tese "Da Transfusão em Clínica Médica" de João Garcia de Almeida Júnior, para concorrer à Livre-Docência de Terapêutica, da Faculdade de Medicina da Universidade do Rio de Janeiro (Figura 4).

Na década de 40, no Rio de Janeiro e em São Paulo, a Hemoterapia brasileira começou a se caracterizar como uma especialidade médica. Em 07 de dezembro de 1942, foi inaugurado o primeiro Banco de Sangue no Instituto Fernandes Figueira, Rio de Janeiro, visando obter sangue para este hospital e atender ao esforço de guerra, mandando plasma humano para os hospitais das frentes de batalha. Foram seus fundadores e organizadores os médicos Mario Pereira de Mesquita, Raymundo Muniz de Aragão e Vera R. Leite Ribeiro. O industrial Francis Hime, filantropicamente, custeou a instalação e manutenção deste serviço.

Também em 1942, em Porto Alegre, foi fundado o Banco de Sangue da Santa Casa, por Guido Bornancini, Heitor Cirne Lima e Rabelo Antoniacci. ${ }^{3}$

Em 1944, o prefeito do então Distrito Federal, Henrique Dosdworth, levou o projeto para formação do Banco de Sangue do Distrito Federal ao presidente Getúlio Vargas, que o sancionou por decreto. Seu primeiro diretor foi Miguel Meira de Vasconcelos (urologista do então prefeito), que convidou para ajudá-lo, entre outros, a médica Maria Brasília Leme Lopes e o estudante de medicina Helio Lopes Costa. A inauguração ocorreu em 25 de novembro de 1944, na Rua Teixeira de Freitas 27, na Lapa, em frente ao Passeio Público. O povo passou a reconhecer o local como Banco de Sangue da Lapa. ${ }^{3}$

Em 1945, Miguel Meira de Vasconcelos fundou um Banco de Sangue privado, em Botafogo, que fornecia sangue aos médicos que faziam transfusões. Chamava-se Banco de Sangue do Rio de Janeiro, mas a razão social era I. Hertz Ltda. Em 12 de janeiro de 1945, Pedro Clovis Junqueira fundou a "Central Hemoterápica" juntamente com Helio Gelli Pereira e o prof. Monteiro de Carvalho. A partir de então, Junqueira passou a dedicar-se, exclusivamente, à Hemoterapia. 
Em 1943, em São Paulo, Oswaldo Mellone fundou e foi chefe do Banco de Sangue do Hospital das Clínicas ligado à Universidade de São Paulo, que marcou época e serviu de exemplo a outros em vários estados, tanto em suas rotinas assistenciais como no desenvolvimento de ensino e pesquisa. Outros pioneiros inovadores e inventivos foram Ruy Faria, o nosso querido Ruifar, que trabalhava no Hospital $\mathrm{Mu}-$ nicipal e na Clínica Infantil do Ipiranga; Humberto Costa Ferreira, vindo da Inglaterra, onde trabalhou com Taylor, introdutor da pesquisa de $\mathrm{Rh}$ em nosso país, trabalhava na Casa Maternal. Na mesma época foi fundado o Banco de Sangue da Santa Casa de Misericórdia de São Paulo, onde Vasco Ferraz Costa, Isaias Zatz, Antonio Damasco, Dante Langhi, Gecel Szterling e Raif Simão faziam parte da equipe médica.

Em 1949, foram fundados o Banco de Sangue de São Paulo, inicialmente no Hospital Santa Catarina, na Avenida Paulista, e depois na Rua Bela Cintra, em prédio próprio, pelos médicos Oswaldo Mellone, Oscar Yahn, Artur Biancalana, Ademar Albano Russi, Magalhães e outros. ${ }^{3}$

Foi na década de 40 que os primórdios da Hemoterapia no Brasil apresentaram destaques científicos importantes, como dois eventos que merecem ser citados:

- O Curso de Hematologia promovido por Walter Oswaldo Cruz, em Manguinhos, uma espécie de pós-graduação da época, no IOC. Neste curso, Pedro Clovis Junqueira e Halley Pacheco de Oliveira foram classificados com aproveitamento excepcional e convidados a trabalhar na Seção de Hematologia, com Walter O. Cruz. ${ }^{4}$

- Em 8 de agosto de 1949, o I Congresso Paulista de Hemoterapia, promovido por Carlos da Silva Lacaz e Oswaldo Mellone, juntou hemoterapeutas e hematologistas, como Carlos Lacaz, Oswaldo Mellone, Ruy Faria, P. C. Junqueira, Michel Jamra e Gastão Rosenfeld. Ali foram lançadas as bases para a fundação da Sociedade Brasileira de Hematologia e Hemoterapia, em $1950 .^{5}$

Também nesta década destacaram-se vários estudos sobre Doença Hemolítica Perinatal e Imuno-hematologia, como os trabalhos de Humberto Costa Ferreira, Oswaldo Mellone e Oscar Yahn, P. C. Junqueira, Carlos Lacaz, F. Ottensooser e Ruy Faria.

Nos anos 50, o fato mais importante foi a fundação da Sociedade Brasileira de Hematologia e Hemoterapia (SBHH), possibilitando a consolidação das duas especialidades irmãs. A fundação ocorreu durante seu primeiro Congresso, presidido por Walter O. Cruz e realizado em Petrópolis, de 21 a 26 de maio de 1950. Um ano após, Michel Jamra presidiu o segundo Congresso da SBHH, no qual foi constituído o primeiro estatuto. Seguiu-se o Congresso de Recife, em 1954, presidido por Darcy Lima, e o IV Congresso, presidido por Côrtes Villela, em Juiz de Fora, durante o qual foi criado o emblema da SBHH, que é utilizado até hoje. ${ }^{6}$

Os especialistas brasileiros começaram a freqüentar congressos internacionais da especialidade e a SBHH foi, pela primeira vez, representada fora do país, em 1951, quando P. C. Junqueira e Oswaldo Mellone, como seus representantes, foram participar do IV ${ }^{\text {me }}$ Congrès International de la Société Internationale de la Transfusion Sanguine (Lisboa, Portugal), hoje ISBT. Em 1954, P. C. Junqueira organizou a delegação brasileira para participar do $\mathrm{V}^{\text {me }}$ Congresso da ISBT, na Sorbonne, em Paris, incentivando os brasileiros a participarem de eventos internacionais em Hemoterapia, estimulando convites para que estrangeiros viessem ao Brasil, para nossos eventos. Como exemplo, neste mesmo ano, A. E. Mourant (UK) passou duas semanas no Rio de Janeiro trocando experiências científicas e depois ministrou um Curso de Imuno-hematologia, em São Paulo, a convite de Carlos da Silva Lacaz, então professor catedrático da USP.

Em 1950, a partir de iniciativa do Banco de Sangue do Distrito Federal, foi promulgada a lei ${ }^{\circ} 1075$, de 27 de março de 1950, que dispõe sobre a Doação Voluntária de Sangue. Também neste ano foi fundada a Associação de Doadores Voluntários do Brasil, cuja primeira presidente foi a Sra. Nair Aranha.

Fato relevante desta época foi a criação da Seção de Investigação Científica do Banco de Sangue da Prefeitura do Distrito Federal, sendo designado como chefe P. C. Junqueira, que, junto com sua equipe, realizou estudos sobre os grupos sangüíneos de populações índias e neobrasileiras, efetuando excursões pelo Brasil e escrevendo trabalhos científicos publicados no Brasil e exterior. Outras iniciativas científicas e educacionais tiveram lugar no Rio de Janeiro, como a realização do primeiro Curso de Hemoterapia no Centro de Estudos da Secretaria Geral de Saúde e Assistência da Prefeitura do Distrito Federal, também coordenado por P. C. Junqueira, com a colaboração de Halley Pacheco de Oliveira, Maria Brasília Leme Lopes, Walter O Cruz e outros.

Estas atividades e a determinação dos especialistas da capital da República fizeram com que, em 1956, o prefeito do Distrito Federal, embaixador Negrão de Lima, transformasse o Banco de Sangue da Prefeitura no Instituto de Hematologia. Em 1959, o Instituto obteve uma área cedida pelo Hospital Pedro Ernesto, possibilitando a instalação de um Serviço de Hematologia com internação hospitalar, por Monteiro Marinho.

Em 1964, o Ministério da Saúde criou um grupo de trabalho para estudo e regulação disciplinadora da Hemoterapia no Brasil, que resultou na formação da Comissão Nacional de Hemoterapia, em 1965, presidida pela Dra. Maria Brasília Leme Lopes, e com representação da Sociedade Brasileira de Hematologia e Hemoterapia pelos Drs Oswaldo Mellone, Francisco Antonáscio e, posteriormente, Jacob Rosenblit.

A Comissão Nacional de Hemoterapia e o Ministério da Saúde, através de decretos, portarias e resoluções, estabeleceu o primado da doação voluntária de sangue e a necessidade de medidas de proteção a doadores e receptores, disciplinou o fornecimento de matéria-prima para a indústria de fracionamento plasmático e a importação e exportação de 
sangue e hemoderivados. Entre as suas atividades destacam-se a implantação de registro oficial dos bancos de sangue públicos e privados, a publicação de normas básicas para atendimento a doadores e para prestação de serviço transfusional e a determinação da obrigatoriedade dos testes sorológicos necessários para segurança transfusional.

Em 1978, pela nova organização estrutural do Ministério da Saúde, a Comissão Nacional de Hemoterapia passou a ser uma das Câmaras Técnicas (decreto n ${ }^{\circ}$ 79.050, de 30 de dezembo de 1977). A Câmara Técnica acabou sendo desativada em 30 de dezembro de 1979 com a criação do Programa Nacional de Sangue e Hemoderivados (Pró-Sangue).

No período de 1964 a 1979, a Hemoterapia no Brasil tinha legislação e normatização adequadas, porém ainda carecia de uma rígida fiscalização das atividades hemoterápicas e de uma política de sangue consistente.

O sistema era desorganizado, com serviços públicos e privados de altíssimo nível técnico e científico convivendo com outros de péssima qualidade, alguns com interesses prioritariamente comerciais. As indústrias de hemoderivados, em geral, estimulavam a obtenção de matéria prima através de doadores remunerados e da prática da plasmaférese. Nem sempre os cuidados com a saúde dos doadores eram prioritários. Em alguns bancos de sangue, de ética questionável, indivíduos das camadas mais pobres da população, que muitas vezes não tinham reais condições físicas e mesmo nutricionais, eram estimulados a doar sangue.

Neste ponto, ressaltamos alguns acontecimentos que culminaram na reorganização do sistema hemoterápico no Brasil:

- A cooperação Brasil- França e o Programa Nacional de Sangue e Hemoderivados.

- ACampanha de Doação Voluntária de Sangue da Sociedade Brasileira de Hematologia e Hemoterapia.

- AConstituição de 1988.

\section{A Cooperação Brasil-França e o Programa Nacional} de Sangue e Hemoderivados

A Cooperação Brasil-França em Hemoterapia iniciouse em 1961, quando o então presidente Jânio Quadros incumbiu Luiz Tavares da Silva, eminente cirurgião pernambucano e professor universitário, de viajar para a França para "comprar" dois bancos de sangue e instalá-los no Rio de Janeiro e em São Paulo, o que acabou não ocorrendo em virtude da renúncia do presidente. No entanto, em 1962, Tavares da Silva viajou à França, e o governo francês colocou à sua disposição quatro bolsas de estudo para especialização em Hematologia e transfusão de sangue. Ao nosso colega Luiz Gonzaga dos Santos foi cedida a primeira bolsa.

Visando a capacitação técnico-científica, principalmente na formação de recursos humanos, o programa Brasil-França foi intensificado em 1977 com a inauguração do Hemocentro de Pernambuco (Hemope). Concebido de acordo com o modelo dos centros franceses de hemoterapia e diri- gido por Gonzaga dos Santos, serviu como base, em 30 de abril de 1980, para a criação do Programa Nacional de Sangue e Hemoderivados ( Pró-Sangue).

O Programa Nacional de Sangue estabelecia uma ordenação do Sistema Hemoterápico no Brasil, criando hemocentros nas principais cidades do País, tendo como diretrizes a doação voluntária não remunerada de sangue e medidas para segurança de doadores e receptores. Foi coordenado inicialmente por Luiz Gonzaga dos Santos, que, com sua determinação e dinamismo, obteve um avanço considerável.

O Programa Nacional de Sangue transformou-se, posteriormente, em Coordenação de Sangue e Hemoderivados, passou do Ministério da Saúde para a Agência Nacional de Vigilância Sanitária e atualmente volta a ser um programa ministerial. ${ }^{7}$

\section{ACampanha de Doação Voluntária de Sangue da Sociedade Brasileira de Hematologia e Hemoterapia}

Em 1979, a Sociedade Brasileira de Hematologia e Hemoterapia era presidida por Celso Carlos de Campos Guerra. Inconformado com a situação das doações de sangue em alguns serviços do Brasil, muitas vezes realizadas por presidiários em troca de cigarros, ou por mendigos em busca da remuneração, estimulou e liderou diversos colegas de São Paulo, entre eles Luiz Gastão Rosenfeld, Jacob Rosenblit, Nelson Hamerschlak, Pedro Maçanobu Takatu e Leonel Szterling, em uma cruzada por todo o País, que culminou em junho de 1980 com a extinção da doação remunerada de sangue no Brasil.

Para atingir este objetivo, Celso teve o apoio de todos os hemoterapeutas do País e contou com a ajuda da comunidade médica e órgãos de classe como a Associação Médica Brasileira, Associação Paulista de Medicina, Associação Paulista de Propaganda, Associação Brasileira de Relações Públicas e da Imprensa de forma geral.

Destaca-se a cooperação do Sr. Rafael Sampaio, designado pela Associação Paulista de Propaganda e que teve um papel fundamental no desenvolvimento de peças publicitárias, anúncios de televisão, revistas e jornais.

Naquela ocasião, a estratégia para a obtenção do doador altruísta, a exemplo de países desenvolvidos, era conseguir o chamado doador de reposição (familiares e amigos dos pacientes) que eram sensibilizados e conscientizados para o ato de doar. Aquilo que parecia impossível aconteceu sem qualquer desabastecimento, que era o principal temor dos organizadores da campanha. O Brasil, que naquela época tinha $80 \%$ de doação remunerada, passou a ter exclusivamente doadores voluntários. ${ }^{8}$

\section{A Constituição de 1988}

O artigo 199 da Constituição aprovada em 1988 estabeleceu que a assistência à saúde é livre à iniciativa privada, e no seu parágrafo 4 diz que a lei disporá sobre as condições e os requisitos que facilitem a remoção dos órgãos, tecidos e 
substâncias humanas para fins de transplante, pesquisa e tratamento, bem como a coleta, processamento e transfusão de sangue e seus componentes, vedado todo tipo de comercialização. Apenas em 2002, a regulamentação legal deste artigo, apresentada por Sergio Arouca, foi aprovada com a proibição da doação gratificada de sangue, conceituando a remuneração dos serviços através da cobertura de custos de processamento.

\section{O Contemporâneo}

A exemplo do que ocorreu em todo o mundo, as principais mudanças no sistema hemoterápico brasileiro não ocorreram nem por intervenção dos especialistas, nem por influência direta do governo, e sim por causas aleatórias como, por exemplo, o advento da AIDS e por razões econômicas.

Em 1981, a Síndrome de Imunodeficiência Adquirida (AIDS) foi reconhecida pelo Centro de Controle de Doenças nos Estados Unidos como entidade nosológica. Posteriormente, foi estabelecido que as transfusões de sangue, componentes e derivados poderiam ser considerados fontes de transmissão. Nos anos 80 , no Brasil, cerca de $2 \%$ dos casos de AIDS eram transmitidos por transfusão e mais de $50 \%$ dos hemofílicos apresentavam-se infectados pelo vírus HIV. O aparecimento da AIDS introduziu novos procedimentos, tais como: a substituição da doação anônima pela personalizada, o incremento de todos os métodos de autotransfusão e a disciplina do uso do sangue, de seus componentes e derivados através de judiciosa avaliação do trinômio riscos/ beneficios/custo. ${ }^{9}$

Um fato novo pode ser introduzido na prática médica, em um tempo menor do que o esperado, mas há sempre dificuldade em sua aceitação devido principalmente a:

- inércia dos médicos em mudarem suas condutas;

- obsolescência da estrutura em que se investiu e que resulta em lucro.

A projeção de uma fato novo para o futuro é feita com maior ou menor probabilidade de acerto. Em 1960, o congelamento de hemácias era o fato novo importante, que resolveria grande número de problemas científicos e logísticos. Previu-se que, após 1975, 80\% das transfusões de hemácias seriam provenientes do congelamento, o que não aconteceu. Em 1985, o Fluosol, potencial substituto do sangue, era promissor e prevendo-se que 30\% das transfusões de hemácias fossem substituídas, o que, também, não aconteceu.

Além disso, outros fatos subverteram a evolução tradicional da Hemoterapia, tais como:

- O conceito de Hemoterapia Clínica: este conceito nasceu no Hospital Universitário da UFRJ, serviço coordenado pelo Prof. Pedro Clóvis Junqueira, no qual o hemoterapeuta, além de administrar o banco de sangue, tinha suas atividades ligadas à assistência aos pacientes e orientação dos colegas das especialidades clínicas e cirúrgicas, consci- entizando-os da utilização adequada dos componentes sangüíneos, seus riscos e benefícios. Este conceito influenciou vários serviços do País, entre eles os dos Hospitais Albert Einstein, Sírio Libanês, Santa Catarina e outros. Nos Estados Unidos, conceituou-se a chamada medicina transfusional, que ainda carece da maior presença do hemoterapeuta junto aos pacientes. ${ }^{10}$

- A contenção do pagamento das despesas médicas: em 1982, o governo Reagan estabeleceu os princípios da medicina gerenciada (managed care), que diminuía os investimentos na área da saúde e criava um novo sistema de pagamento das despesas médicas por procedimentos e não pelo gasto real. Os serviços hospitalares, de diagnóstico e tratamento, de fonte de lucro passaram a ser fonte de despesas. No Brasil, estes princípios foram introduzidos pelo INPS e posteriormente adotados pelo SUS e pelos convênios. Os fatores econômicos são sempre prevalentes...

- Ocrescente desenvolvimento da Genética Molecular e a Biotecnologia: a Genética Molecular permitiu o conhecimento da estrutura, composição e função do DNA e do RNA, o que tornou possível o esclarecimento da patogenia de inúmeras doenças. Seus avanços são notáveis e alguns deles marcantes e decisivos para o futuro. Na Hemoterapia estes avanços já se refletem em novos testes diagnósticos e em produtos recombinantes.

- O advento de novas terapêuticas celulares: envolve o desenvolvimento de separação e cultura de células com uso de fatores de crescimento, citoquinas e anticorpos monoclonais. No Brasil, estas técnicas utilizadas em Serviços de Hemoterapia propiciam um maior desenvolvimento dos Centros de Transplantes de Células Tronco-Hematopoéticas.

- A renovação dos equipamentos: é constante e crescente. Acredita-se que o crescimento de novos equipamentos de alta tecnologia seja da ordem de $30 \%$ ao ano, obrigando os Serviços de Hemoterapia a uma constante renovação.

- A automação e computação: apresenta aplicabilidade em processos científicos, educacionais e administrativos. Permite maior eficiência e precisão nos processos administrativos de uma organização.

- Os sistemas da qualidade: crescimento do número de serviços de Hemoterapia e Bancos de Sangue do Brasil que buscam processos administrativos adequados, documentados e seguros com o princípio de melhoria contínua ou aperfeiçoamento visando superar as expectativas dos pacientes. Observamos um incremento constante do número de serviços credenciados e acreditados por entidades nacionais e internacionais. 
- A pulverização das atividades da Hemoterapia em diversas sociedades científicas: com o expressivo avanço científico da Hemoterapia dos últimos anos, o interesse dos profissionais da área distribuiu-se em atividades de diversas sociedades científicas. Nos países mais desenvolvidos verificamos a participação do hemoterapeuta em áreas de imunohematologia, hemostasia e trombose, terapia celular e transplantes.

\section{Conclusão}

A hemoterapia brasileira desde os seus primórdios demonstra a busca por uma organização e modelo característico de nosso país. Destacam-se o pioneirismo das artesanais transfusões realizadas por alguns cirurgiões na tentativa de salvar vidas, a criação dos primeiros Serviços de Transfusão nos anos 40, o advento da Sociedade Brasileira de Hematologia e Hemoterapia em 1950, a Campanha da Doação Voluntária da SBHH de 1980 e o Programa Nacional de Sangue com a criação de hemocentros. Hoje vivemos uma hemoterapia acoplada à hematologia, inclusive nos curriculuns universitários; Serviços de Hemoterapia de excelência na maioria dos hospitais e hemocentros de qualidade. O hemoterapeuta vam deixando um papel passivo tornando-se um especialista de destaque na comunidade médica, hospitalar e universitária, implementando tecnologia e conhecimento em benefício dos pacientes. A nova fronteira que é apresentada à hemoterapia no século XXI relaciona-se a tudo aquilo que a medicina considera hoje como ciência de ponta, como a biologia molecular, a engenharia genética e a terapia celular.

\footnotetext{
Abstract

Blood transfusion had two major periods: one empiric to 1900, and another scientific from 1900 on. In 1879, in Brazil, a report discussed if the best transfusion would be between animals and men or between human beings. The pioneers of hemotherapy were surgeons of Rio de Janeiro. Around 1920, there were the first very simple but organized services. During the 40's, we highlight Rio de Janeiro's Blood Transfusion Service (Seviço de Transfusão de Sangue - STS), that held both assistencial and scientific activities. At the end of that decade, there was the 1st Sao Paulo Hemotherapy Congress (1 Congresso Paulista de Hemoterapia), that provided the basis to the Brazilian Hematology and Hemotherapy Society (Sociedade Brasileira de Hematologia e Hemoterapia), in 1950. In 1965, thanks to Brazilian Health Ministry, the National Hemotherapy Commission was created, thus establishing rules to protect blood donors and patients. Then, we get to 1979 with a desorganized and uneven quality system. During the 80's with the establishment of a National Blood Policy, the altruistic donation Program and the 1980 Brazilian Contitution, Hemotherapy could reach another level. Then we get to AIDS era and we head to new concepts and care. Furthermore, there were new concepts of clinical hemotherapy, economic factors, biotecnology, cell therapy, new equipment, computers, quality systems
}

and the increasing study of state-of-the-art scientific areas. Rev. bras. hematol. hemoter. 2005;27(3):201-207.

Key words: History of blood transfusion; blood banks; hemotherapy in Brazil.

\section{Referências Bibliográficas}

1. Marcondes JV. Transfusão de Sangue. Tese apresentada à Faculdade de Medicina do Rio de Janeiro 1879;73-77.

2. Maciel H. Contribuição para a Organização dos Serviços de Transfusão de Sangue. Brasil Médico 1937;44:1.093-1.103.

3. Rosenblit J, Barison M, Santos LG, Maciel H. Informações pessoais no ano 2000 .

4. Junqueira, PC. Walter Oswaldo Cruz (1910-1957). Rev Bras Hematol Hemoter 2002;24(2)155-157.

5. Lorenzi TF, Jamra M (in memorian). História da Hematologia Brasileira. Fundação Maria Cecília Souto Vidigal. São Paulo 2002, 137-138.

6. Guerra CCC. 50 anos da Sociedade Brasileira de Hematologia e Hemoterapia. Rev Bras Hematol Hemoter 2000;22(2):67.

7. Santos LG. Hemope e Pró-Sangue duas decisões um caminho EDUPE. Recife-PE 2002.

8. Guerra CCC. Fim da doação remunerada. Rev Bras Hematol Hemoter $2005 ; 27(1): 1-3$.

9. Hamerschlak N, Pasternak J. Doenças transmissíveis por transfusão. ANDREI. São Paulo, 1991.

10. Junqueira PC. O Essencial da Transfusão de Sangue. ANDREI. São Paulo, 1979.

Avaliação: Editor e dois revisores externos.

Conflito de interesse: não declarado

Recebido: 18/07/2005

Aceito após modificações: 28/07/2005 